Full-length Article

\title{
Forced swimming sabotages the morphological and synaptic maturation of newborn granule neurons and triggers a unique pro-inflammatory milieu in the hippocampus
}

\author{
María Llorens-Martín*, Jerónimo Jurado-Arjona, Marta Bolós, Noemí Pallas-Bazarra, Jesús Ávila* \\ Centro de Biología Molecular Severo Ochoa (CSIC-UAM), c/ Nicolás Cabrera 1, 28049 Madrid, Spain \\ Centro de Investigación Biomédica en Red sobre Enfermedades Neurodegenerativas (CIBERNED, ISCIII), c/ Valderrebollo 5, Madrid, Spain
}

\section{A R T I C L E I N F O}

\section{Article history:}

Received 1 October 2015

Received in revised form 23 December 2015

Accepted 23 December 2015

Available online 24 December 2015

\section{Keywords:}

Adult hippocampal neurogenesis

Retrovirus

Acute stress

Forced swimming

Inflammation

Microglia

\begin{abstract}
A B S T R A C T
Recent experimental data suggest that mood disorders are related to inflammatory phenomena and have led to the "inflammatory hypothesis of depression". Given that the hippocampus is one of the most affected areas in these disorders, we used a model of acute stress (the Porsolt test) to evaluate the consequences of forced swimming on two crucial events related to the pathophysiology of major depression: the functional maturation of newborn granule neurons; and the hippocampal inflammatory milieu. Using PSD95:GFP-expressing retroviruses, we found that forced swimming selectively alters the dendritic morphology of newborn neurons and impairs their connectivity by reducing the number and volume of their postsynaptic densities. In addition, acute stress triggered a series of morphological changes in microglial cells, together with an increase in microglial CD68 expression, thus suggesting the functional and morphological activation of this cell population. Furthermore, we observed an intriguing change in the hippocampal inflammatory milieu in response to forced swimming. Importantly, the levels of several molecules affected by acute stress (such as Interleukin- 6 and eotaxin) have been described to also be altered in patients with depression and other mood disorders.
\end{abstract}

(c) 2015 Elsevier Inc. All rights reserved.

\section{Introduction}

New neurons are continuously generated in the brain of vertebrates throughout adulthood. Under physiological conditions, this process occurs in two neurogenic regions, namely the subventricular zone of lateral ventricles and the subgranular zone (SGZ) of the hippocampal dentate gyrus (DG). It is widely accepted that adult hippocampal neurogenesis (AHN) is involved in learning and memory (Garthe et al., 2009). In addition, growing evidence indicates that newborn neurons are crucial elements in the regulation of mood and affective behavior. On the one hand, the discovery of the pro-neurogenic effect of antidepressants (Malberg et al., 2000), and, on the other, the observation that increasing AHN is required for the manifestation of the behavioral effects of antidepressants (Santarelli et al., 2003) elicited the 'adult neurogenesis hypothesis' of depression. However, the mechanisms bidirectionally regulating the influence of AHN on mood and vice versa seem

* Corresponding authors at: Centro de Biología Molecular "Severo Ochoa", Universidad Autónoma de Madrid, c/ Nicolás Cabrera 1, 28049 Madrid, Spain.

E-mail addresses: m.llorens@csic.es (M. Llorens-Martín), javila@cbm.csic.es (J. Ávila). to be complex and not exempt of controversy (for an example compare (Santarelli et al., 2003) and (Meshi et al., 2006)).

Major depression (MD) is a highly relevant public health issue worldwide. In the past, the monoaminergic hypothesis was the most widely accepted theory explaining depression. However, increasing evidence suggests that MD is related to distinct peripheral and central pro-inflammatory mechanisms (Abelaira et al., 2014; Ceretta et al., 2012; Dantzer et al., 2008; Hoyo-Becerra et al., 2014; Iseme et al., 2014; Menard et al., 2015; Schiepers et al., 2005). Interestingly, some patients suffering from MD show increased levels of pro-inflammatory cytokines, such as IL-1, IL-6, IFN- $\gamma$, and TNF- $\alpha$ (Dantzer et al., 2008; Maes et al., 2015; Schiepers et al., 2005; Tavakoli-Ardakani et al., 2015). These observations and other lines of evidence have led to the establishment of the "inflammatory hypothesis" of depression (Huang and Lin, 2015; Maes et al., 2015). One of the most important mechanisms by which stress has been proposed to induce a pro-inflammatory state in the brain is via the increase in glucocorticoid (GC) expression (Horowitz et al., 2015). GCs are known to be elevated after forced swimming and to mediate the behavioral effects of the Porsolt test (Veldhuis et al., 1985). Although GCs inhibit microglial cell activity in vitro, they increase microglial proliferation in vivo 
(Nair and Bonneau, 2006; Madrigal et al., 2003). In addition, both chronic stress and GCs prime microglial cells and increase their pro-inflammatory response to various insults (Nair and Bonneau, 2006; Tynan et al., 2010).

Microglial cells are macrophage resident cells that are rapidly activated in response to damage or infections. These cells perform multiple roles including, but are not limited to, surveillance, pathogen recognition, phagocytosis, and synapse pruning and remodeling (Kettenmann et al., 2013; Paolicelli et al., 2014). In addition, the interaction between microglial and neural precursor cells is crucial during AHN (Sierra et al., 2010) and development (Paolicelli et al., 2014).

In general terms, stress is a known potent stimulator of microglial activation and pro-inflammatory cytokine secretion (Cheng et al., 2015; Lee et al., 2015) and a negative regulator of AHN (Gould et al., 1992). Although the consequences of forced swimming on the inflammatory hippocampal milieu have been addressed previously (Hellwig et al., 2015; Sugama et al., 2007), to the best of our knowledge, the link between these changes in microglial activation and the functional maturation of newborn hippocampal neurons has not been studied so far in this model. In this regard, here we analyzed the specific features of this microglial activation and its effects on the maturation of newborn hippocampal granule neurons in a model of acute stress caused by forced swimming. We found that forced swimming drastically impaired the morphological and functional maturation of newborn neurons. Furthermore, it altered microglial activation and triggered changes in the hippocampal inflammatory milieu. Although most of the molecules whose levels appeared to be increased by forced swimming had a pro-inflammatory nature, strong chemoattractant, phagocytic, and neuroprotective components were also observed. This change in the pattern of inflammatory mediators, in turn, may orchestrate the impaired maturation of newborn neurons, a cell population that is damaged in mood and neurodegenerative disorders. These data might be relevant given that inflammation produces long-term alterations in newborn neuron and hippocampal functionality (Llorens-Martin et al., 2014). In addition, the levels of these molecules are also altered in animal models of chronic stress (Frank et al., 2014), and, most relevantly, in patients with MD (Domenici et al., 2010; Maes et al., 2015; Merendino et al., 2004; Tavakoli-Ardakani et al., 2015), thereby suggesting that the alterations in the inflammatory milieu induced by stress are related to the etiological factors behind MD development.

\section{Material and methods}

\subsection{Animals and experimental design}

Six-week-old female C57BL/6JRcc mice were obtained from Harlan Laboratories. Animals were subjected to a 2-week habituation period before the experiments began. They were housed in a specific pathogen-free colony facility in accordance with European Community Guidelines (directive 86/609/EEC) and handled following European and local animal care protocols. The detailed experimental design and the description of the experimental groups are shown in Supplementary Fig. S1. Briefly, one group of mice ( $n=3$ per experimental condition) was used to determine the plasma corticosterone levels immediately after the Porsolt test. These levels were compared with those of untreated mice in order to ensure that this manipulation truly represents acute stress for the animals (Supplementary Fig. S1 A). In addition, two independent groups of 14 mice ( $n=7$ per experimental condition) were used for biochemical, histological and molecular determinations (Supplementary Fig. S1 B). These two independent groups of ani- mals were used to perform a Cytokine Protein Array twice. In this type of determination, all the animals belonging to the same experimental condition must be grouped and the resulting mixture is incubated on a single membrane. Hence, for the purpose of statistical comparisons, these arrays were performed on two independent groups of 7 mice. Finally, a group of 4 mice per experimental condition was used for retroviral injections (Supplementary Fig. S1 C). All animals were 4 months old when sacrificed.

\subsection{Retroviral stock preparation}

We used a retroviral stock (PSD95-GFP) encoding for GFP fused to PSD95 (Kelsch et al., 2008). The PSD95-GFP retrovirus allowed postsynaptic cluster visualization (green channel). Moreover, anti-GFP immunohistochemistry (red channel) allowed visualization of the whole dendritic tree (Kelsch et al., 2008). The plasmids used to produce the PSD95-GFP retrovirus were kindly provided by Prof. Carlos Lois (University of Massachusetts). Retroviral stocks were concentrated to working titers of $1 \times 10^{7}-2 \times 10^{8} \mathrm{pfu} / \mathrm{ml}$ by ultracentrifugation (Zhao et al., 2006). Since the retroviruses used are engineered to be replication-incompetent, only dividing cells at the time of surgery can be infected (Kelsch et al., 2008; Zhao et al., 2006).

\subsection{Stereotaxic surgery}

Mice were anesthetized with Isoflourane and placed in a stereotaxic frame. Coordinates $(\mathrm{mm})$ relative to bregma in the anteroposterior, mediolateral, and dorsoventral axes were as follows: dentate gyrus (DG) $[-2.0,1.4,2.2]$. $2 \mu \mathrm{l} / \mathrm{DG}$ of virus solution was infused at a rate of $0.2 \mu \mathrm{l} / \mathrm{min}$ via a glass micropipette. Animals were 8 weeks old at the time of retroviral injections.

\subsection{Forced swimming (the Porsolt test)}

Two months after retroviral injections, the Porsolt test was used to induce high-intensity acute stress in animals. In the case of those animals not subjected to the retroviral injections, the Porsolt test was also performed at 4 months of age. Animals were placed in a 12 -cm-diameter and 29-cm-tall cylinder filled with water at $23{ }^{\circ} \mathrm{C}$ for $6 \mathrm{~min}$ on two consecutive days. Behavior was recorded and then assigned to categories, following Detke et al. (Detke et al., 1995): climbing, swimming, and immobility. As previously described (Llorens-Martin et al., 2007), we considered climbing as the vertical position of the mouse with repetitive movement of the limbs, the forelegs striking the glass walls, both hind legs swinging in the water at the same time. We considered swimming to be the more horizontal position of the animal, the hind legs treading water and a clear displacement of the body. To avoid considering the passive displacement of the body through inertia of previous movements as swimming, we took into consideration the movement of legs, as proposed by Gersner et al., (Gersner et al., 2005). The different behaviors were quantified during the two consecutive days of the Porsolt test and are shown in Fig. 1A. The behavioral quantification was performed on all the animals subjected to the Porsolt test $(n=17)$.

\subsection{Sacrifice}

Twenty-four hours after the last session of the Porsolt test, mice were fully anesthetized by means of an intraperitoneal injection of pentobarbital and transcardially perfused with saline followed by $4 \%$ paraformaldehyde in phosphate buffer. Brains were removed and post-fixed overnight in the same fixative. Animals used for biochemical and histological determinations were perfused with saline. The left hemisphere was immediately dissected and frozen, 

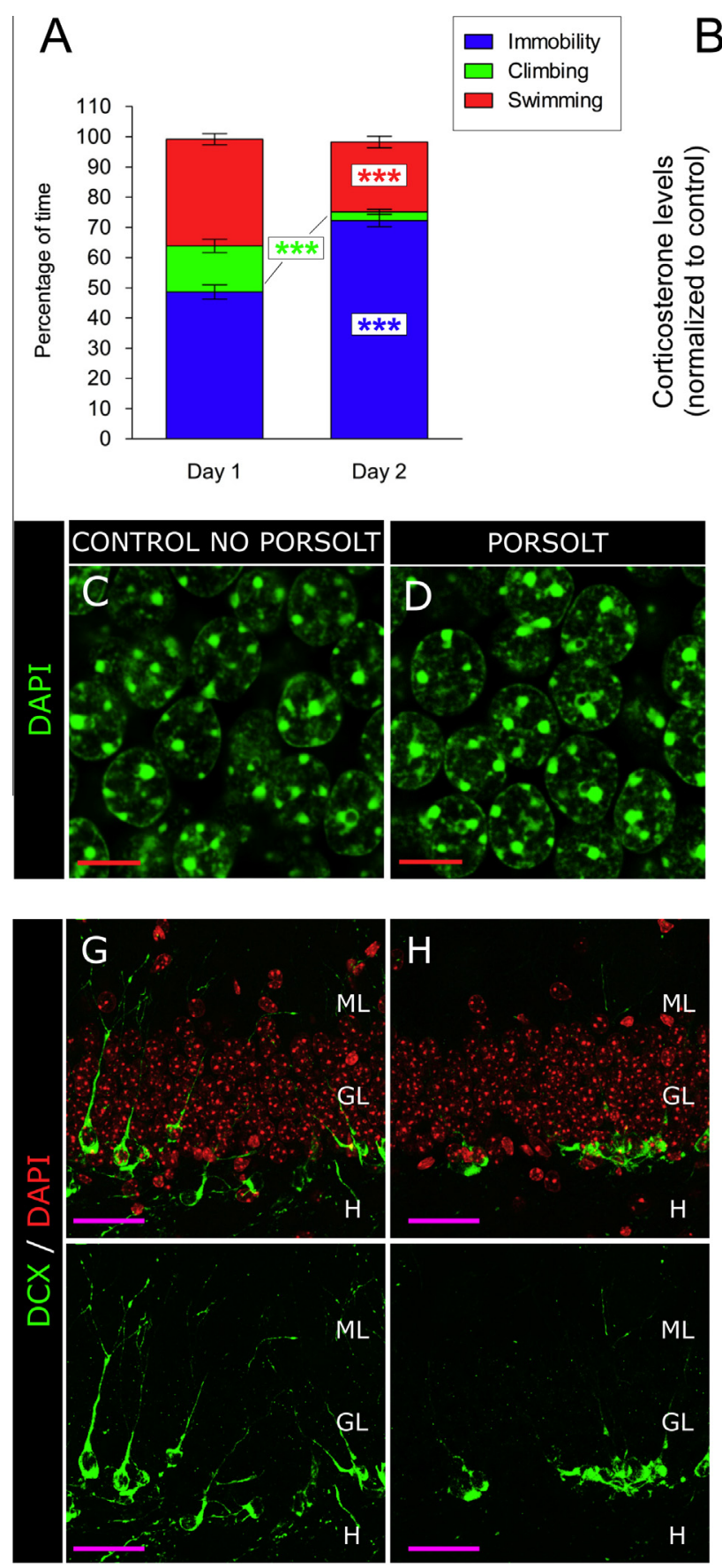

B Climbing Swimming

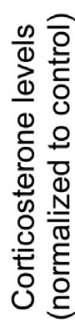

60 $\square$ Control No Porsolt Porsolt

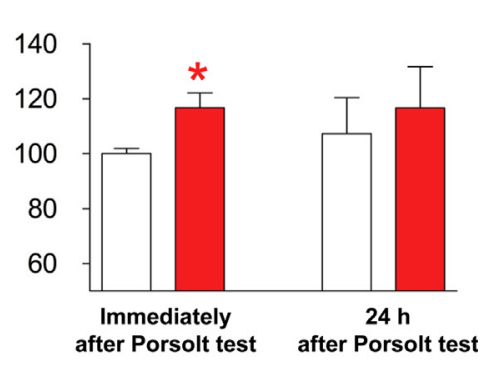

$\mathrm{E}$

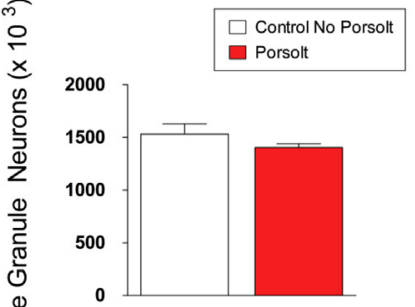

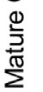

$F$

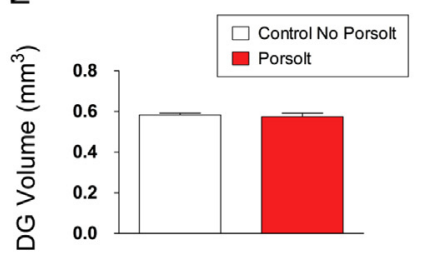

I

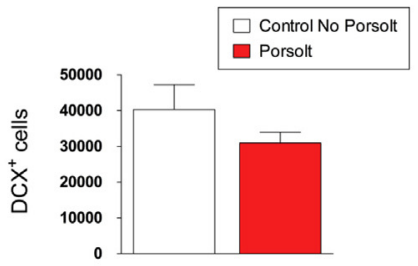

]

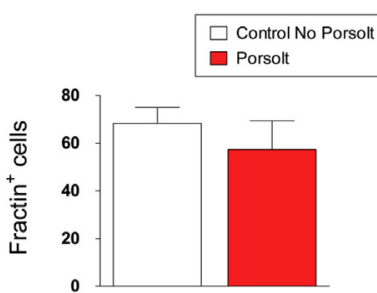

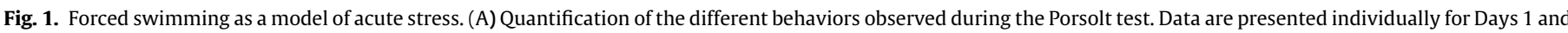

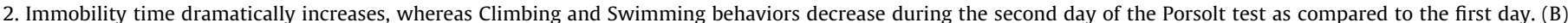

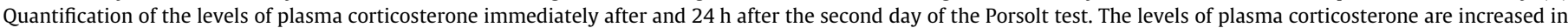

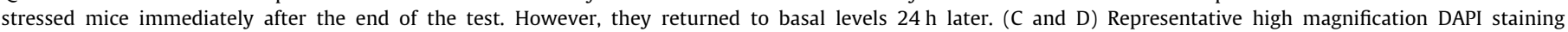

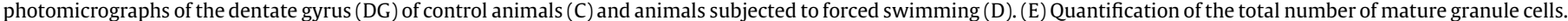

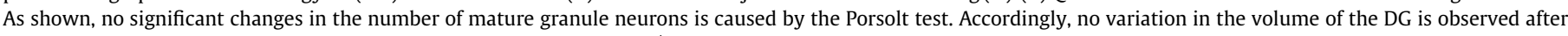

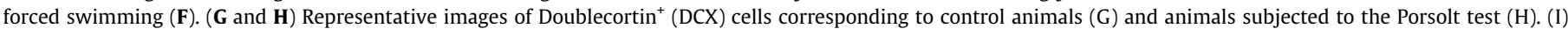

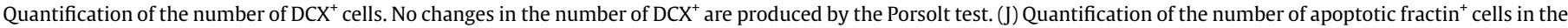

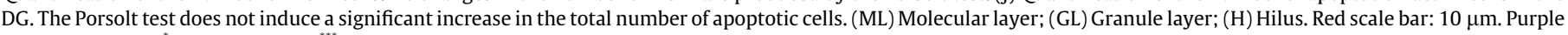
scale bar: $50 \mu \mathrm{m} .{ }^{*} 0.05>p \geqslant 0.01 ;{ }^{* * *} 0.001 \geqslant p$.

whereas the right hemisphere was fixed overnight in $4 \%$ paraformaldehyde for later use in histological determinations.

\subsection{Immunoassays}

The levels of plasma corticosterone were assayed with a commercial enzyme-linked immunosorbent assay (ELISA) (Enzo LifeS- ciences, Catalog number ADI-900-097) following the manufactureŕs instructions. The sensitivity of this ELISA is $27.0 \mathrm{pg} / \mathrm{ml}$ (range $32-20,000 \mathrm{pg} / \mathrm{ml}$ ). Briefly, animals were fully anesthetized by means of an intraperitoneal injection of pentobarbital, and blood was extracted by cardiac punction. Serum was obtained after centrifuging blood at $11,000 \mathrm{rpm}$ for $5 \mathrm{~min}$. Corticosterone determination was performed on 3 animals per 
experimental condition immediately after the Porsolt test (Supplementary Fig. S1 A). In addition, it was measured $24 \mathrm{~h}$ after the last session of the Porsolt test in 7 animals per experimental condition-these belonging to Group B described in Supplementary Fig. S1 B.

The hippocampal expression of Interleukin-6 was determined by a commercial Mouse ELISA kit (Abcam, catalog number ab100713-IL6). Right hemisphere hippocampi of Group B animals represented in Supplementary Fig. S1 B were dissected on ice, and protein extraction was performed following the manufactureŕs instructions. The sensitivity of this ELISA is $<2 \mathrm{pg} / \mathrm{ml}$ (range $0.82-$ $600 \mathrm{pg} / \mathrm{ml})$.

\subsection{Immunohistochemistry}

Sagittal brain sections ( $50 \mu \mathrm{m}$ thick) were obtained on a Leica VT1200S vibratome. Immunohistochemistry was performed as described previously (Llorens-Martin et al., 2013). For all the immunohistochemical analyses, series of brain slices were made up randomly of one section from every ninth. The following primary antibodies were used: rabbit anti-GFP (Molecular Probes (Invitrogen), 1:1000); rabbit anti-Iba1 (Wako, 1: 500); goat antiDCX (Santa Cruz, 1:500); rabbit anti-fractin (BD Biosciences, 1:500); and rat anti-CD68 (Abcam, 1:500). The following secondary Alexa-conjugated antibodies were used at a final concentration of 1:1,000: Donkey Alexa 555-conjugated anti-rabbit (Life Technologies); Donkey Alexa 488-conjugated anti-rabbit, (Life Technologies); and Donkey Alexa 647-conjugated anti-goat (Life Technologies). All sections were counterstained with DAPI (Calbiochem, 1:5,000).

\subsection{Volume estimation of the dentate gyrus (DG)}

To measure the DG volume, we used a semi-automatic Cavalieri system (ImageJ v.1.47, NIH, USA, http://rsbweb.nih.gov/ij/) in 50$\mu \mathrm{m}$ sections stained with Toluidine blue, as previously described (Llorens-Martin et al., 2013).

\subsection{Cell counts}

Microglial $\left(\mathrm{Iba}^{+}\right)$cells, apoptotic $\left(\right.$fractin $\left.^{+}\right)$cells, immature $\left(\mathrm{DCX}^{+}\right)$neuroblasts, and mature granule neurons were counted under a LSM710 Zeiss confocal microscope $(63 \times$ Oil immersion objective) using the physical dissector method adapted for confocal microscopy (Llorens-Martin et al., 2013).

\subsection{Morphometric analysis}

(a) Morphometric analysis of retrovirus-infected newborn neurons: Three series of sections from each animal were used for the immunohistochemical detection of GFP. At least fifty randomly selected neurons were reconstructed under a LSM710 Zeiss confocal microscope $(25 \times$ Oil immersion objective). Confocal stacks of images were obtained ( $Z$-axis interval: $1 \mu \mathrm{m}$ ), and $\mathrm{z}$-projections were analyzed for the determination of total dendritic length and Sholĺs analysis.

(b) Morphometric analysis of microglial cells: One series of sections from each animal was used for the immunohistochemical detection of Iba1. Only Iba $1^{+}$microglial cells located in the granule layer were selected for morphometric analysis. At least 50 randomly selected cells were reconstructed under a LSM710 Zeiss confocal microscope (40× Oil immersion objective) for the morphometric analysis in each experimental condition. Confocal stacks of images were obtained ( $Z$-axis interval: $1 \mu \mathrm{m}$ ), and z-projections were analyzed for the determination of total prolongation length and Sholl's analysis. The area of the nucleus was measured on image Z-projections. The nuclei of at least $280 \mathrm{Iba}^{+}{ }^{+}$microglial cells per experimental condition were analyzed. The number of phagocytic pouches and the percentage of cells with such pouches were estimated from $300 \mathrm{Iba}^{+}{ }^{+}$microglial cells per experimental condition. The quantification of phagocytic pouches in DG microglial cells has been reported previously (Sierra et al., 2010) and has been performed by analyzing each merged single plane images (DAPI and Iba1 channels) of the stacks in order to assess the presence of phagocytic inclusions.

All cells were traced using the NeuronJ plugin for ImageJ software (ImageJ v.1.47, NIH, USA, http://rsbweb.nih.gov/ij/). Sholl's analysis was performed using the plugin ShollAnalysis for ImageJ.

\subsection{Number and size of PSD95-GFP $P^{+}$clusters}

PSD95-GFP ${ }^{+}$clusters were examined in each dendritic tree branching order. A minimum of 30 segments belonging to each experimental condition were analyzed for each order. Confocal stacks of images were obtained in a LSM710 Zeiss confocal microscope (63× Oil immersion objective, $x y$ dimensions: $67.4 \mu \mathrm{m})(Z-$ axis interval: $0.13 \mu \mathrm{m}$ ). Two-channel stack Z-projections were obtained. The dendritic length of each segment was measured (red channel, GFP), and the number and size (area) of PSD-GFP ${ }^{+}$ clusters was analyzed using the semi-automatic Particle Analyzer plugin for ImageJ (green channel). For postsynaptic density (PSD) area analysis, a minimum of 1500 PSDs belonging to each experimental condition were examined for each branching order.

\subsection{Quantification of CD68 expression in microglial cells}

CD68 is a marker of microglial activation related to microglial phagocytosis (Walker et al., 2013). In order to address the activation of microglial cells by acute stress, CD68 expression was quantified by immunohistochemistry in the DG microglial cells. Briefly, confocal stacks of 20 images were obtained under a LSM710 Zeiss confocal microscope ( $40 \times$ Oil immersion objective) ( $Z$-axis interval: $1 \mu \mathrm{m}$ ). Three-channel images were acquired (DAPI (blue), CD68 (green) and Iba1 (red)). Max z-projections were obtained in Image software. For each image, a fixed value threshold was applied to the red (Iba1) channel, and then a Mean filter (2 pixels) was applied in order to remove small precipitates of the secondary antibody. The threshold image was converted in a Selection, which was loaded into the CD68 channel. Selections were inverted in both channels, and the exterior of the cells were filled with black paint. Resulting images were then processed with the Just Another Colocalization Plugin (JACOP) in ImageJ. The percentage of colocalization between the two channels was calculated. The percentage of Iba $1^{+}$ area that was also $\mathrm{CD}^{+} 8^{+}$is shown in the graphs.

\subsection{Cytokine antibody array}

One longitudinally sectioned half of the left hippocampus from the animals shown in Supplementary Fig. S1 B were homogenized, and protein concentration was estimated using the BCA Protein Assay Kit (Pierce, Rockford, IL). For each independent group (namely A and B), a pooled protein extract for each experimental condition was prepared in a single tube. The total protein concentration was determined for each mouse in order to ensure an equal amount of protein corresponding to each animal in the prepared mixture. For each independent group of animals, two membranes were assayed-one corresponding to mice subjected to the Porsolt test and the other one to control untreated animals. This procedure was done independently for each group of mice in order to allow statistical comparisons of the results obtained.

The mouse cytokine array (RayBio ${ }^{\circledR} \mathrm{C}$-series Mouse Cytokine Antibody Array C1000; Ray Biotech Inc., Norcross, GA) consisted 
of 96 soluble signaling factors and cytokine antibodies spotted in duplicate onto a PVDF membrane. The membranes were blocked with $10 \%$ bovine serum albumin in PBS and subsequently incubated with samples overnight at $4{ }^{\circ} \mathrm{C}$. The membranes were washed with buffer supplied by the manufacturer and exposed to 500 -fold diluted biotin-conjugated anti-cytokine antibodies at room temperature for $2 \mathrm{~h}$. They were then washed, incubated with a 1000-fold diluted HRP-conjugated streptavidin for $1 \mathrm{~h}$, and immersed for $1 \mathrm{~min}$ in a peroxidase substrate solution. For each spot, the net density of the gray level was normalized by subtracting the background from the total raw density using the Chemidoc XRS system and ImageJ analysis software. For each group of animals, the relative levels of each cytokine were calculated. Next, statistical comparisons between the values obtained were made. The data from the two independent groups of mice were compared by using a Student $t$-test. Mean \pm SE were represented in the graphs.

\subsection{Quantitative polymerase chain reaction ( $q P C R$ )}

One longitudinally sectioned half of the right hippocampus obtained from the animals belonging to Group B shown in Supplementary Fig. S1 B were used to isolate total RNA with the QIAzol Lysis Reagent (Qiagen) and RNeasy Mini kit (Qiagen). Reverse transcription (RT) of $20 \mathrm{ng} / \mathrm{ul}$ RNA was performed using the High capacity cDNA Reverse Transcription kit (Applied Biosystems). qPCR was developed on a AB 7900HT cycler (Applied Biosystems) (384-multi-well plates). 5 ng of cDNA per well was run in triplicate. Data were obtained using the Pfaffl method. The commercial Taqman probes (Applied Biosystems) used are detailed in Supplementary Fig. S4 A.

\subsection{Statistical analysis}

Statistical analysis was performed using the SPSS 17.0.1 software (SPSS, 1989; Apache Software Foundation). The Kolmogorov-Smirnov test was used to test the normality of the sample distribution. A non-parametric test (Mann-Whitney $U$ test) was applied in those cases in which normality could not be assumed. In the case of normal sample distribution, data were analyzed by a one-way ANOVA or Student's $t$-test. For the comparison of qualitative variables, a Pearson $\chi$-Squared test was applied.

\section{Results}

\subsection{Forced swimming as an acute stress model}

Supplementary Fig. S1 shows the detailed experimental design and the experimental groups. Fig. 1A shows the quantification of the behaviors observed during the two consecutive days of the Porsolt test. As shown, Immobility time on the second day was significantly higher than on the first $(U=5.00 ; p<0.0001)$. In contrast, both Climbing $(U=17.50 ; p<0.0001)$ and Swimming $(U=28.50$; $p<0.0001$ ) were drastically reduced during the second day of the test.

In order to ensure the stressful nature of this manipulation, the levels of plasma corticosterone were measured by ELISA at two time points. Fig. 1B shows that the circulating levels of corticosterone were increased in mice subjected to the Porsolt test when measured immediately after the finalization of the second day $(t=0.021)$. However, they returned to basal levels $24 \mathrm{~h}$ later.

The Porsolt test caused no alterations in the total number of mature granule neurons $(U=9.00 ; p=0.239$ ) (Fig. $1 \mathrm{~B}-\mathrm{D})$ nor in DG volume $(U=14.00 ; p=0.931)$ (Fig. $1 \mathrm{E})$. Nor did the total number of $\mathrm{DCX}^{+}$neuroblasts change after the test $(U=10.00 ; p=0.69)$ (Fig. $1 \mathrm{~F}-\mathrm{H}$ ). In addition, as observed in Fig. 1I, the stress induced by the test was not strong enough to trigger a net increase in the total number of apoptotic fractin ${ }^{+}$cells $(U=12.00 ; p=0.662)$, as previously described (Llorens-Martin and Trejo, 2011). These data prove that the Porsolt test is an acute stress model that causes no severe alterations in the global structure of the DG.

\subsection{Forced swimming alters the morphology of newborn granule neurons}

Fig. 2 shows the quantification of the morphological alterations induced by the Porsolt test on newborn granule neurons. In Fig. 2A and B, representative images of 2-month-old newborn granule neurons labeled with the PSD95-GFP retrovirus are shown. Forced swimming reduced the total dendritic length $(U=1619.00$; $p=0.003$ ) (Fig. 2C). In addition, it drastically modified the morphology of the dendritic tree, as revealed by Sholl's analysis (Fig. 2D). In particular, this activity increased dendritic branching between 0 and $50 \mu \mathrm{m}$ from the soma $\left(F_{1,131}=28.024 ; p<0.0001\right)$, but reduced it between 150 and $200\left(F_{1,134}=7.012 ; p=0.009\right)$, 200 and $250\left(F_{1,128}=36.589 ; p<0.0001\right)$ and $250-300 \mu \mathrm{m}$ from the soma $\left(F_{1,135}=6.551 ; p=0.012\right)$. According to these modifications in dendritic tree structure, acute stress reduced the length of the primary apical dendrite of newborn granule neurons $(U=2766.00 ; p<0.0001)$ (Fig. 2E) and increased the percentage of granule neurons with more than one apical primary dendrite $\left(\chi^{2}=12.474 ; p=0.001\right)$ (Fig. $\left.2 \mathrm{~F}\right)$. Interestingly, acute stress increased the distance migrated by newborn granule neurons within the granule layer $(U=3950.5$; $p<0.0001)$ (Fig. 2G). Taken together, these data indicate that forced swimming profoundly alters the morphology of newborn granule neurons.

\subsection{Forced swimming causes alterations in the number and size of PSDs of newborn granule neurons}

Fig. 3A and B show representative images of 8-week-old newborn granule neurons labeled with the PSD95-GFP retrovirus and their high-power magnifications, in which the structure of PSDs can be observed. Forced swimming reduced the density of PSDs in most of the dendritic tree (2nd $\left(\mathbf{F}_{1,50}=3.030 ; p=0.088\right)$, 3rd $\left(F_{1,53}=10.652 ; p=0.002\right)$, 4th $\left(F_{1,53}=5.227 ; p=0.026\right)$ and 5 th $\left(F_{1,48}=17.169 ; p<0.0001\right)$ branching orders) (Fig. 3C).

In addition, forced swimming led to a decrease in the average area of the PSD. In Fig. 3D, a frequency histogram shows how the percentage of small PSDs is increased in stressed as compared to control mice. To further study these alterations, the average area of the PSD was calculated for each branching order of the dendritic tree (Fig. 3F-H). Forced swimming reduced the average area of the PSD in all orders (2nd $\left(F_{1,1034}=6.180 ; p=0.013\right)$, 3rd $\left(F_{1,2109}=1.518 ; p=0.218\right)$, 4th $\left(F_{1,2034}=18.446 ; p<0.0001\right)$ and 5th $\left(F_{1,2810}=58.319 ; p<0.0001\right)$ branching orders $)$.

To study whether these alterations in the afferent connectivity of newborn neurons were related to global changes in afferent inputs to the molecular layer, the expression of vGLUT1, GAD65, PSD95 and Gephyrin was measured independently in the inner, medium, and external molecular layer (IML, MML and EML), as indicators of glutamatergic (vGLUT1) and GABAergic (GAD65) terminals, and glutamatergic (PSD95) and GABAergic (Gephyrin) synapses, by means of immunofluorescence intensity. No changes were observed in any of the aforementioned regions for any of the markers described (Fig. 3I-L).

It is therefore possible to conclude that acute stress causes a selective alteration in the PSDs of newborn granule neurons that is not accompanied by changes in the global afferent inputs to the molecular layer. 

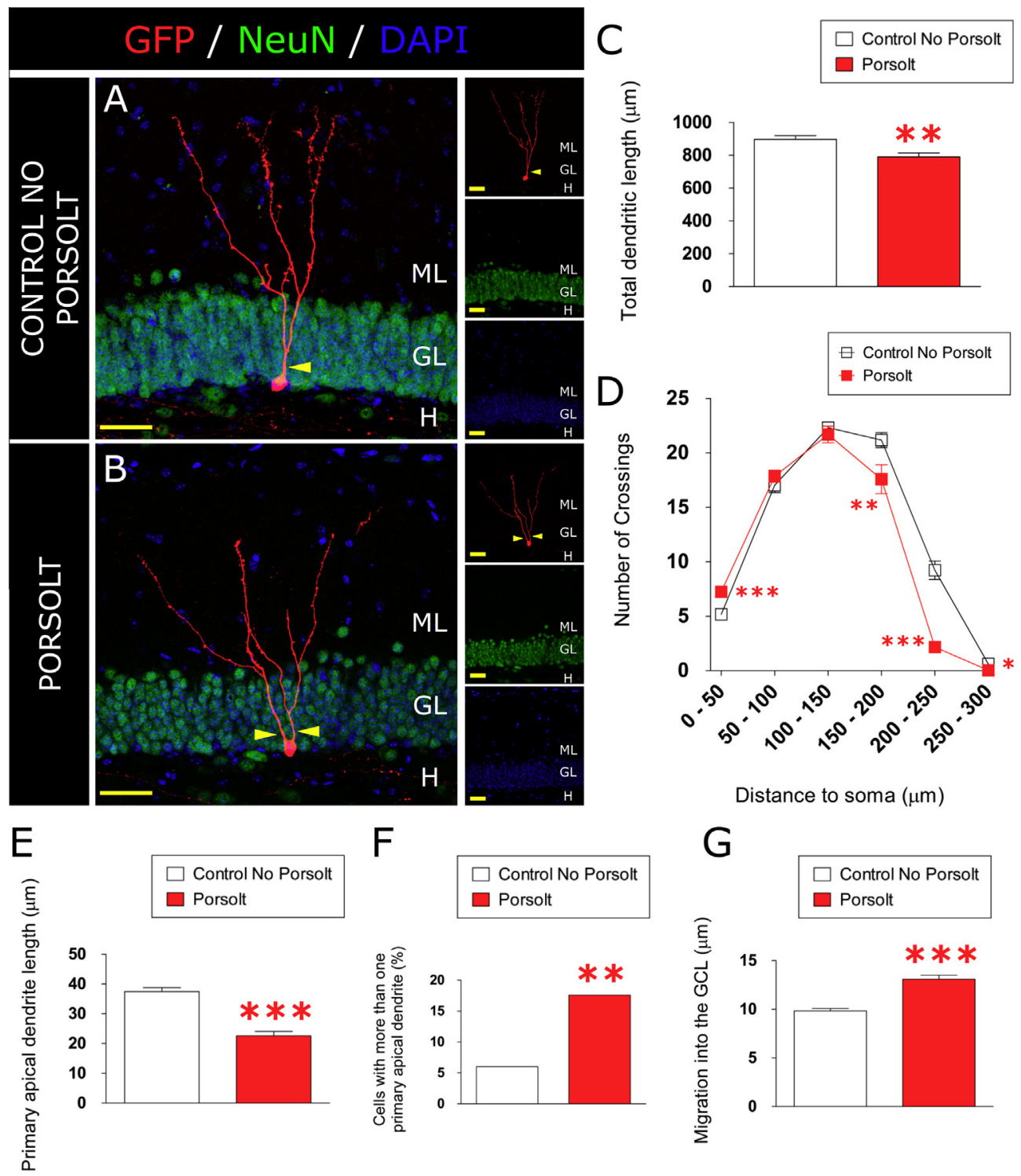

Distance to soma $(\mu \mathrm{m})$

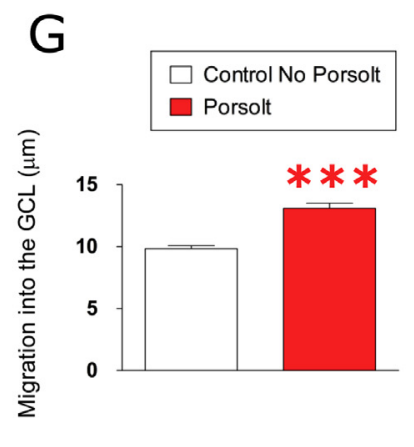

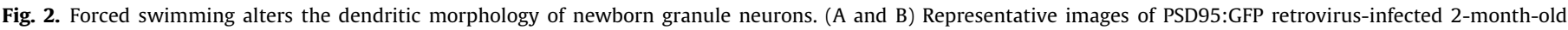

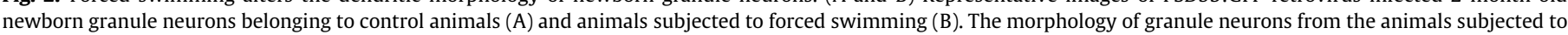

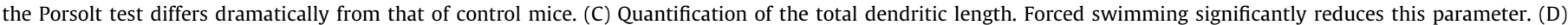

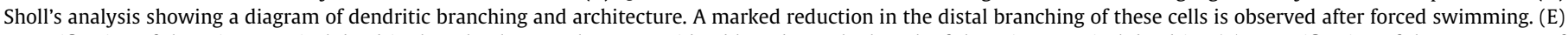

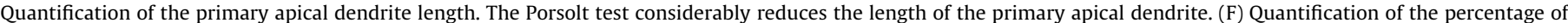

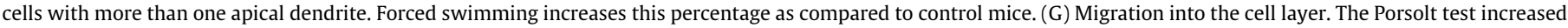

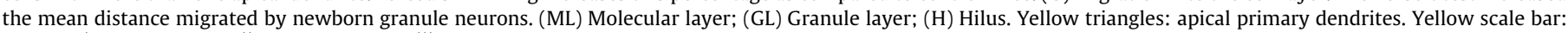
$100 \mu \mathrm{m} .{ }^{*} 0.05>p \geqslant 0.01 ;{ }^{* *} 0.01>p \geqslant 0.001 ;{ }^{* * *} 0.001 \geqslant p$.

\subsection{Forced swimming triggered the activation of microglial cells}

Fig. 4 shows representative images of the hippocampus stained with an anti-Ionized Calcium-binding adapter molecule 1 (Iba1) antibody as a marker of microglial cells and belonging to control animals (A-C) and animals subjected to the Porsolt test (E-G). Forced swimming significantly increased the number of microglial Iba $1^{+}$cells in the DG (Fig. 4I).

In addition, a detailed morphometric analysis of $\mathrm{Iba} 1^{+}$microglial cells was performed. Representative tracings of these cells belonging to either control (D) or stressed $(\mathrm{H})$ mice can be observed. The Porsolt test triggered a drastic morphological change in Iba $1^{+}$microglial cells. Indeed, it increased the area of the nucleus $(U=27187.500 ; p<0.0001)$, the total length of prolongations $(U=101.00 ; p<0.0001)$, the number of branches $((0-10 \mu \mathrm{m}$
$\left(F_{1,93}=53.761 ; \quad p<0.0001\right), \quad 10-20 \mu \mathrm{m} \quad\left(F_{1,105}=60.276\right.$; $p<0.0001), \quad 20-30 \mu \mathrm{m} \quad\left(F_{1,97}=64.835 ; \quad p<0.0001\right), \quad 30-40 \mu \mathrm{m}$ $\left(F_{1,103}=25.531 ; \quad p<0.0001\right), \quad 40-50 \mu \mathrm{m} \quad\left(F_{1,100}=21.880\right.$; $p<0.0001)$ and $50-60 \mu \mathrm{m}\left(F_{1,99}=14.944 ; p<0.0001\right)$ from cell soma), the number of phagocytic pouches per cell $(U=42297.50$; $p=0.001$ ), and the percentage of cells with one or more phagocytic pouches $\left(\chi^{2}=12.991 ; p=0.011\right)$. These data support the notion that acute stress causes the morphological activation of microglial cells.

In addition to the morphological changes induced by forced swimming on the morphology of $\mathrm{Iba}^{+}$cells, we questioned whether these changes would be accompanied by alterations in the expression of markers of microglial activation (Fig. 5). With this aim, we determined the expression of CD68, a marker of the microglial activation, in $\mathrm{Iba} 1^{+}$cells. Fig. $5 \mathrm{~A}$ and $\mathrm{B}$ show representa- 


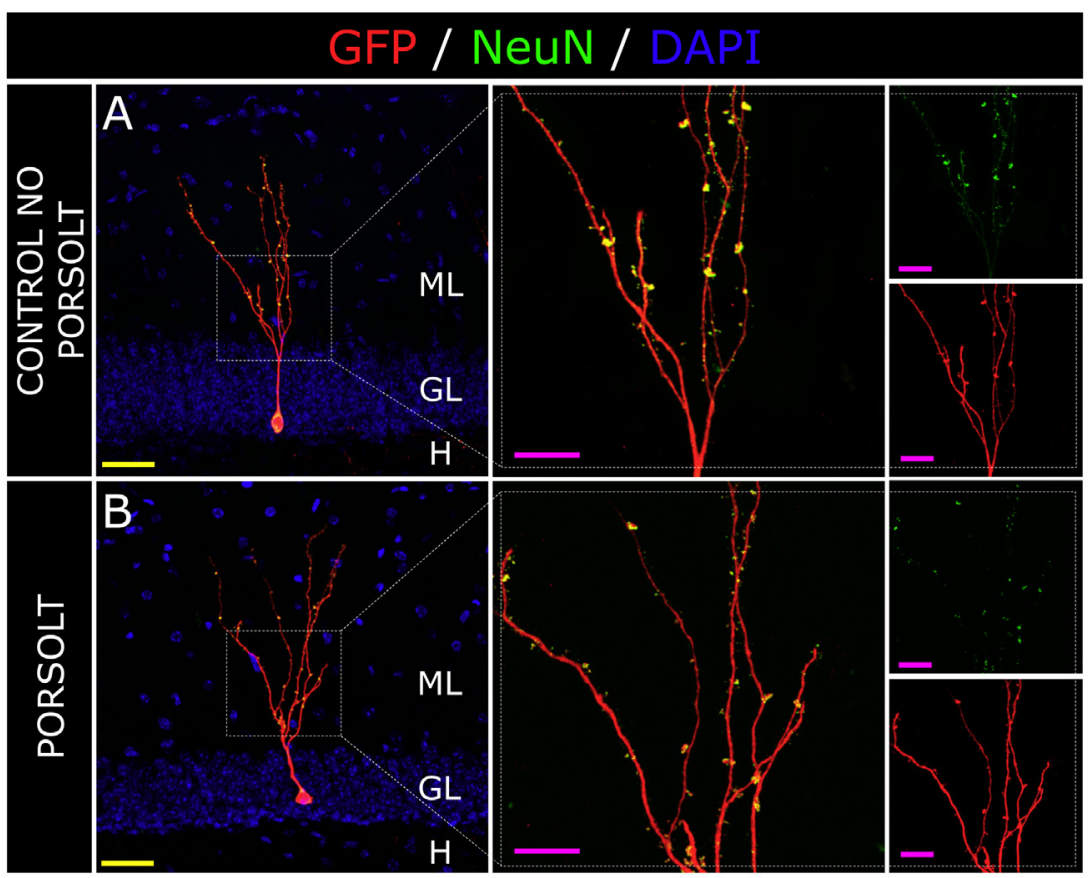

C
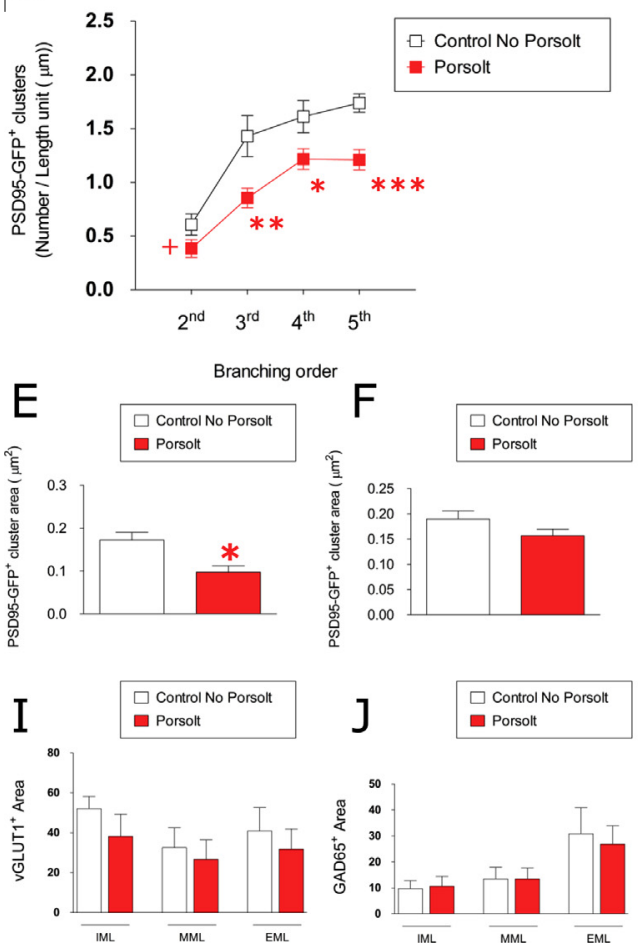

D
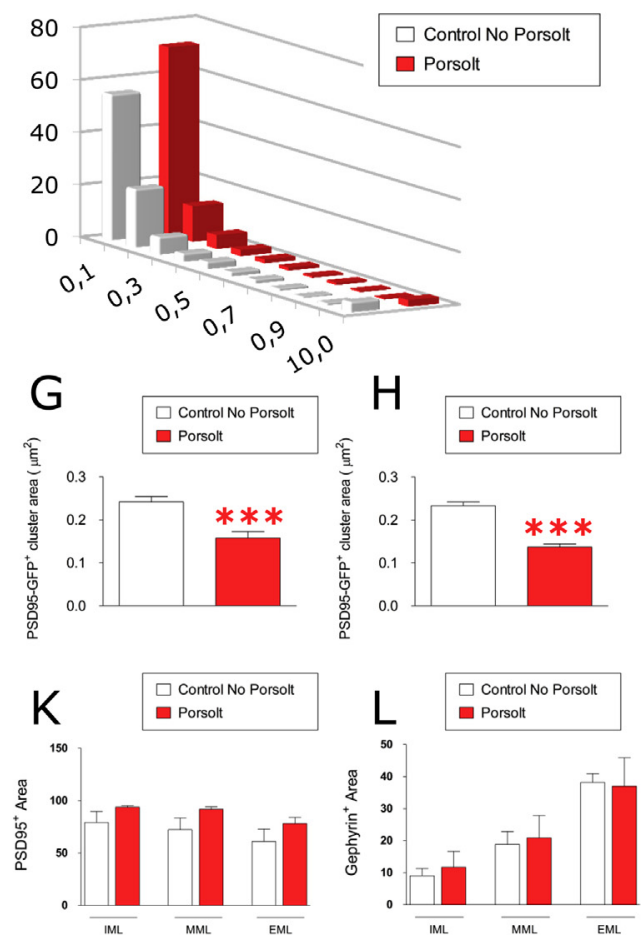

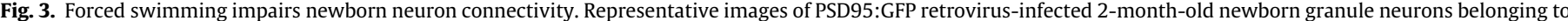

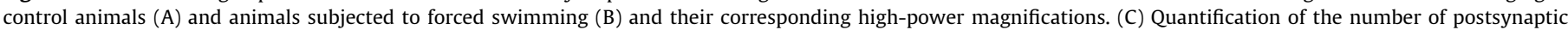

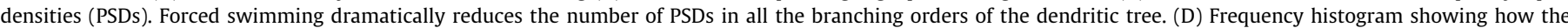

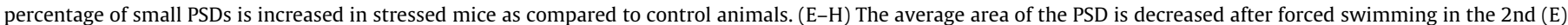

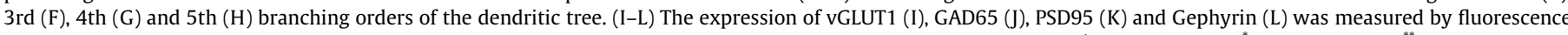

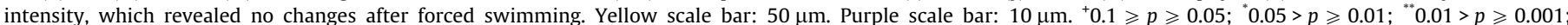
$0.001 \geqslant p$

tive images of double Iba1/CD68 immunohistochemistry in the hippocampus of control (A) and stressed (B) animals. Importantly, the Porsolt test resulted in increased expression of CD68 in microglial cells $(U=0.000 ; p=0.024)$ (Fig. $5 \mathrm{C})$, thus suggesting the functional activation of these cells in response to forced swimming.
3.5. Forced swimming causes changes in the inflammatory microenvironment in the DG

In order to further study the putative changes induced by forced swimming in the hippocampal inflammatory milieu, we measured 


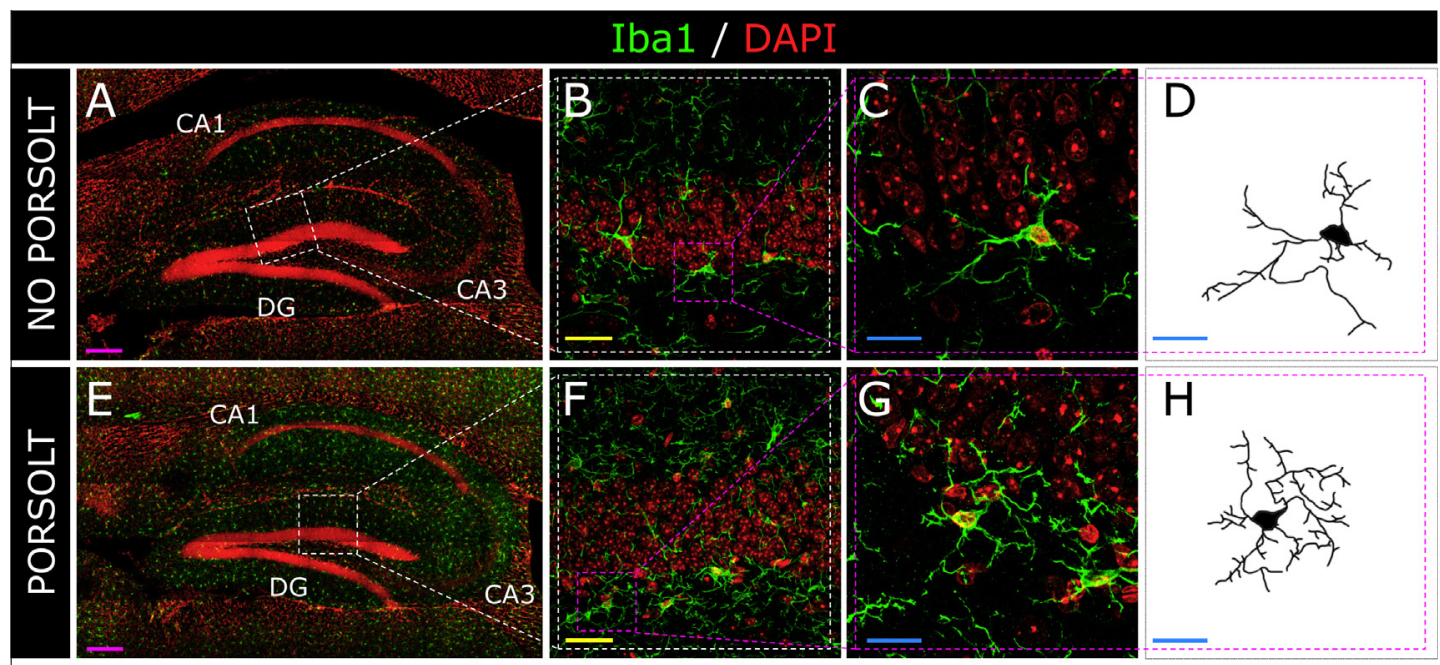

I
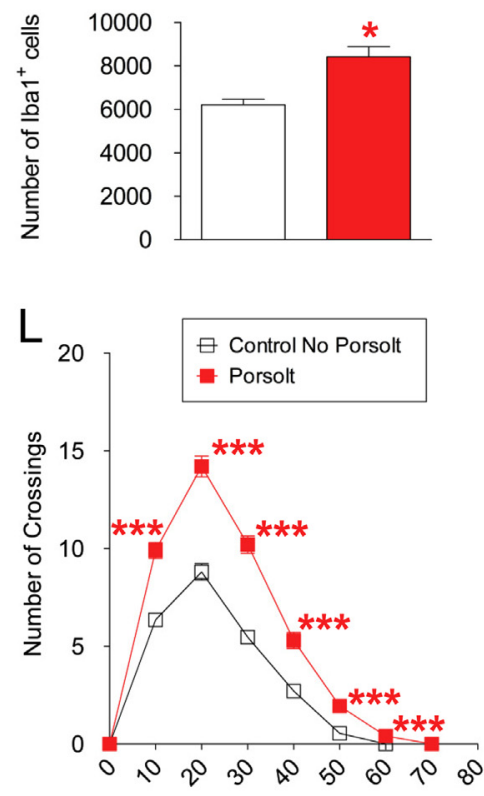

J
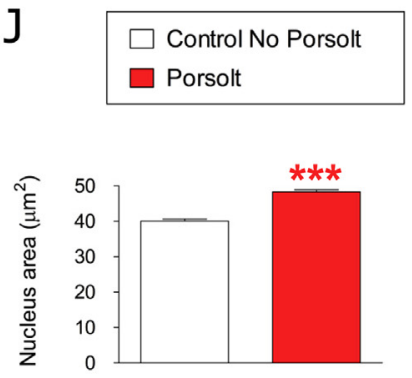

M
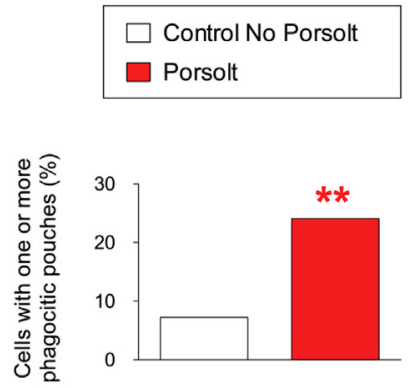

$\mathrm{K}$
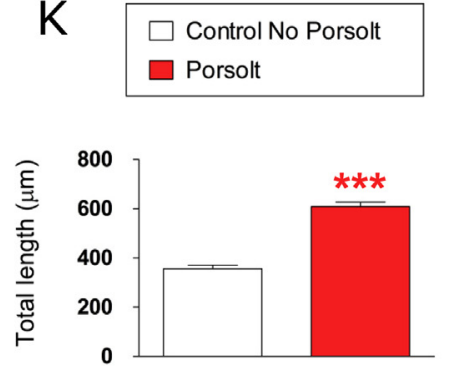

$\mathrm{N}$

Distance to soma $(\mu \mathrm{m})$

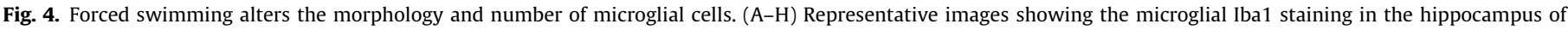

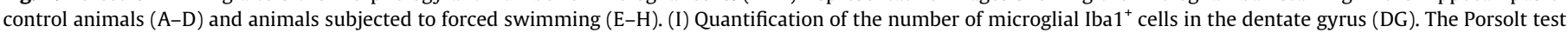

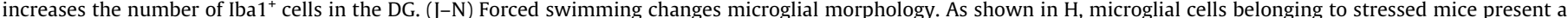

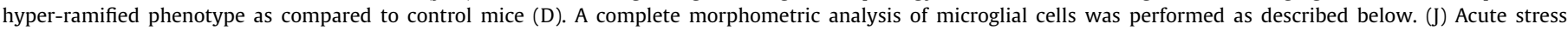

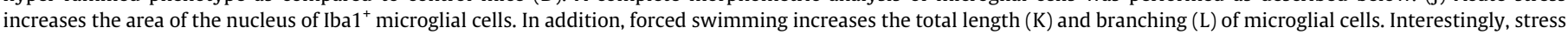

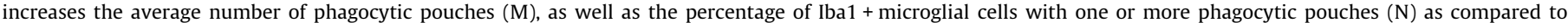
unstressed mice. Purple scale bar: $100 \mu \mathrm{m}$. Yellow scale bar: $50 \mu \mathrm{m}$. Blue scale bar: $20 \mu \mathrm{m}$. $0.05>p \geqslant 0.01 ;{ }^{* *} 0.01>p \geqslant 0.001 ;{ }^{* * *} 0.001 \geqslant p$.

the hippocampal levels of IL-6 by ELISA. As shown in Fig. 5D, the Porsolt test increased the levels of this cytokine in the hippocampi of stressed mice $(U=6.000 ; p=0.017)$.

In addition, we performed a cytokine protein array on two independent groups of mice (Supplementary Figs. S2 and S3). Only those changes with statistical significance are shown in Supplementary Fig. S2 A. The levels of the remaining molecules are represented in Supplementary Fig. S3.

The expression of several growth factors and their receptors (Insulin-like growth factor I and II (IGF-I $(p=0.038)$ and IGF-II
( $p=0.028$ ) respectively), IGF-I binding proteins 2 and 6 (IGFBP2 $(p=0.0045)$ and IGFBP6 $(p=0.045)$ respectively), and basic Fibroblast growth factor (bFGF) $(p=0.0061))$ were altered by forced swimming. In addition, decreases in the levels of proteins related to angiogenesis and tissue-remodeling (such as Vascularendothelial growth factor receptor 3 (VEGFR3) $(p=0.036)$ ), metalloproteinase 2 (MMP-2) $(p=0.025)$, tissue-inhibitor of metalloproteinase $2($ TIMP-2) $(p=0.025)$ and inactive pro-metalloproteinase 9 (pro-MMP-9) $(p=0.028)$ ) were observed after mice were subjected to the Porsolt test. 


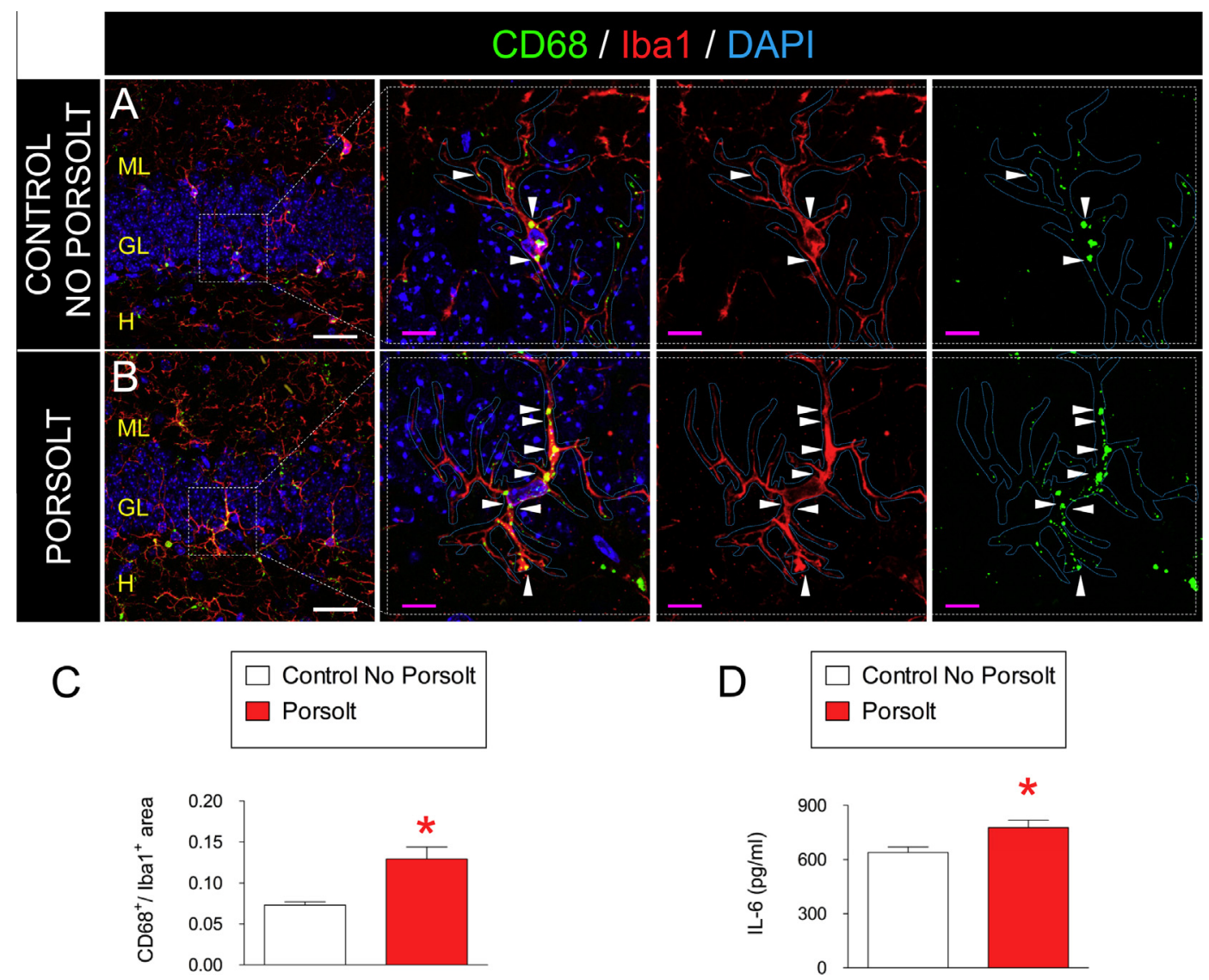

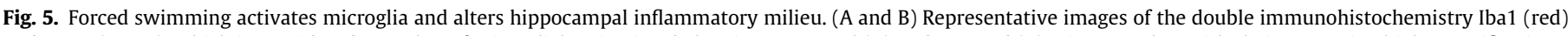

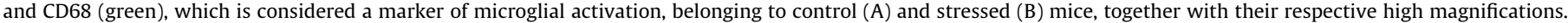

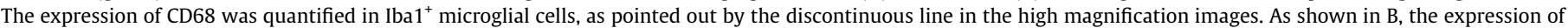

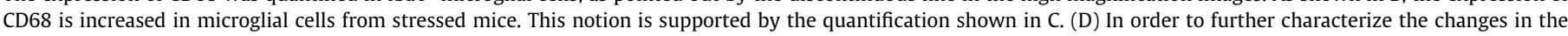

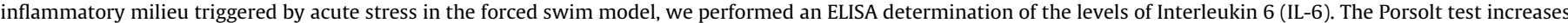
the hippocampal levels of IL-6. White triangles: $\mathrm{CD}^{+} 8^{+}$clusters. White scale bar: $50 \mu \mathrm{m}$. Purple scale bar: $10 \mu \mathrm{m}$. ${ }^{*} 0.05>p \geqslant 0.01$.

Both pro- (Interleukin 6 (IL-6) $(p=0.038)$, Interleukin $1 \alpha($ IL- $1 \alpha)$ $(p=0.0007)$, Interleukin $2($ IL-2) $(p=0.022)$, Interleukin 9 (IL-9) $(p=0.058)$ and eotaxin $(p=0.045)$ ) and anti- (such as Interleukin 3 (IL-3) $(p=0.056)$ and Interleukin 10 (IL-10) $(p=0.045)$ ) inflammatory cytokines showed increased expression after acute stress. Only IL-7 ( $p=0.0011)$ was reduced by acute stress-an observation consistent with what has been described in patients with depression (Lehto et al., 2010).

The expression of chemoattractant (Granulocyte-colony stimulating factor $(\mathrm{G}-\mathrm{CSF})(p=0.0025)$, Lymphotactin $(p=0.045)$, and CD40 $(p=0.020)$ ), adhesion (I-CAM) $(p=0.0019)$ and proproliferative (Axl kinase) $(p=0.046)$ proteins was altered in stressed mice. Interestingly, a member of the tumor necrosis factor (TNF) family (the soluble TNF receptor II (sTNFRII) $(p=0.037)$ ) showed increased levels after forced swimming.

Finally, the expression of some of these proteins was evaluated at the mRNA level by qPCR. Although the expression of IL- 6 and eotaxin-1 was higher in stressed mice, no statistical significance was observed for any of the genes analyzed, as shown in Supplementary Fig. S4.

Taken together, these data indicate that forced swimming causes a substantial alteration in the pattern of cytokines, growth factors, chemokines, and chemoattractant proteins present in the hippocampus, as will be further addressed in the Discussion section.

\section{Discussion}

\subsection{Forced swimming as a model of acute stress. General effects on the} hippocampus

Among the regulators of AHN, stress emerges as one of the most potent inhibitors of this process. In this regard, chronic stress inhibits the proliferation, survival, and differentiation of granule neurons (Cameron and Gould, 1994; Gould et al., 1992). In particular, the type of acute stress studied here, namely forced swimming induced by the Porsolt test, although increasing the circulating levels of GCs ((Veldhuis et al., 1985) and our own data), does not produce massive apoptotic cell death or changes in the number of mature granule neurons or DG volume, but rather triggers GC-dependent and selective apoptotic cell death of certain immature granule cell subpopulations (Llorens-Martin and Trejo, 2011). In line with this, here we demonstrate that forced swimming selectively alters the maturation of newborn granule neurons. This impairment occurs via shrinkage of the dendritic tree of these cells and disruption of their dendritic synaptic connectivity. Although the hippocampal expression of PSD95 did not appear to be altered by the Porsolt test, a selective decrease in the number and size of PSDs was observed in newborn granule neurons. This finding may indicate that this cell population is particularly sensitive to the negative effects of acute stress. 
4.2. Forced swimming impairs the morphological maturation of newborn neurons

During differentiation, newborn neurons exhibit a progressively increased dendritic tree complexity and project their axons towards the CA3 (Zhao et al., 2006) and CA2 (Llorens-Martin et al., 2015) regions. Several insults of diverse natures compromise the morphological maturation of these cells (Fitzsimons et al., 2013; Llorens-Martin et al., 2013, 2014). In this regard, stressinduced apoptosis and dendritic alterations are mediated by GCs in an NMDA-dependent manner (Moghaddam et al., 1994). The knock-down of GC receptor in hippocampal precursor cells has been shown to alter newborn neuron morphology (Fitzsimons et al., 2013). Gould, Woolley and McEwen (Gould et al., 1990; Woolley et al., 1990) were the first to describe that short-term GC manipulations induce dendritic remodeling. These results were obtained by using a non-selective Golgi staining technique. Hence, to the best of our knowledge, the present study is the first to use retroviruses to specifically evaluate the effects of forced swimming on newborn neuron maturation.

Given that we have previously demonstrated that inflammation alone is able to induce dendritic tree shrinkage in newborn granule neurons (Llorens-Martin et al., 2014), it is reasonable to hypothesize that the combined effect of the increased levels of corticosterone and pro-inflammatory mediators acts coordinately to impair the morphological maturation of newborn neurons after exposure to acute stress.

\subsection{Forced swimming impairs newborn neuron connectivity}

During neuronal maturation, dendritic spines are observed for the first time on newborn neurons around post-retroviralinjection day 11 (Zhao et al., 2006), and dendritic excitatory synapses appear around the third or fourth week of cell life (Kelsch et al., 2008). Fitzsimons et al. (Fitzsimons et al., 2013) elegantly demonstrated that the knock-down of GC receptor in hippocampal precursor cells causes a significant increase in the number of dendritic spines in mature newborn neurons. Consequently, the reduction in the afferent glutamatergic connectivity we observed in newborn neurons after forced swimming could be related to excessive activation of GC receptor in these cells, since newborn granule neurons show high expression of both GC and mineralocorticoid receptors (Garcia et al., 2004; LlorensMartin and Trejo, 2011).

Furthermore, we and others have demonstrated that peripheral pro-inflammatory stimuli themselves activate microglia and produce a persistent alteration in the PSDs of newborn neurons (Llorens-Martin et al., 2014). Indeed, recent evidence suggests that microglia play a crucial role in monitoring and maintaining synapses and synaptic activity (Kettenmann et al., 2013; Trapp et al., 2007). The finding that microglia processes make frequent and transient contact with synapses (Wake et al., 2009), together with the high levels of neurotransmitter receptors found on the surface of microglial cells (Pocock and Kettenmann, 2007), suggests that microglial cells surveil synaptic function and are involved in synapse pruning and maturation (Tremblay and Majewska, 2011). In fact, Paolicelli et al. (Paolicelli et al., 2014) demonstrated that these cells engulf and eliminate synapses during development.

\subsection{Forced swimming induced microglial activation}

It has been demonstrated that both chronic (Hellwig et al., 2015; Kreisel et al., 2014; Milior et al., 2015) and acute (Frank et al., 2007; Kreisel et al., 2014; Sugama et al., 2007) stress trigger microglial functional and morphological activation (for a complete review, see (Walker et al., 2013)). In particular, the consequences of the Porsolt test on the morphology of microglia have recently been addressed by Hellwig et al. (Hellwig et al., 2015). Those authors showed a hyper-ramified phenotype of microglial cells after 5 days of forced swimming. We have confirmed these results, observing that the microglial cells showed increased branching in Sholl's analysis and increased nucleus area and exhibited a hyper-ramified phenotype after 2 sessions of forced swimming. Interestingly, changes in microglial morphology have previously been related to depressive-like behaviors in mice and rats (Walker et al., 2013). In line with this, the treatment with the anti-depressant Venlafaxine restored the depressive-like behavior, as well as the morphological alterations in microglial cells induced by forced swimming (Hellwig et al., 2015). Interestingly, the initial increased proliferation and morphological changes induced in microglial cells are dynamically regulated and precede the massive microglial apoptosis caused by chronic stress (Kreisel et al., 2014). Kreisel et al., in fact, elegantly demonstrated that microglial cells are subjected to dynamic changes during different phases of stress protocols. For instance, these authors showed that the number and activation of microglial cells increased after the two initial days of an unpredictable stress protocol, whereas the opposite effects take place after a prolonged period of chronic unpredictable stress (Kreisel et al., 2014). In line with this, other authors also found that chronic stress reduced microglial branching (Milior et al., 2015). Although transgenic mice lacking CX3CR1 and a different acute stressor were used in the work by Kreisel et al., these authors found a shortening of individual processes triggered by acute stress, in line with the hyper-ramified phenotype we have described after forced swimming. In addition, Sugama et al., demonstrated that acute stress induced rapid and robust changes in microglial morphology in several relevant brain areas (Sugama et al., 2007). These authors found that $30 \mathrm{~min}$ of restrain stress significantly increased microglial cell surface area, as well as the total number of activated microglial cells in the hippocampus. Taken all these data into account, it is possible to conclude that both chronic and acute stress dynamically regulate the morphological activation of microglial cells.

Importantly, several works demonstrate that acute stress reduces the expression of the microglia quiescence marker CD200 (Frank et al., 2007; Kreisel et al., 2014). It is important to note that while other studies failed to demonstrate an increase in the global hippocampal expression of the microglial activation marker CD68 after sub-chronic stress (Hinwood et al., 2013), the confocal-implemented method we describe here has allowed us to perform the measurements in the selective region of the DG and in individual microglial cells, thus enabling us to detect these subtle changes in microglial functional activation, in addition to the morphological changes reported. Thus, on the basis of our findings, we conclude that acute stress triggered by forced swimming induces the morphological alteration and functional activation of microglial cells. These changes may be related to the morphological and synaptic alterations described in newborn neurons. Importantly, the increase in the expression of CD68, together with the increased number of phagocytic pouches observed in microglial cells, is suggestive of increased microglial functional activation in the DG after forced swimming.

\subsection{Acute stress induces changes in the general hippocampal inflammatory and neurotrophic environment}

Stress increases the levels of numerous pro-inflammatory cytokines (Cheng et al., 2015; Lee et al., 2015; Madrigal et al., 2003; Nguyen et al., 1998; Slusarczyk et al., 2015), especially in certain brain areas such as the hippocampus (Nair and Bonneau, 2006; Tynan et al., 2010). Acute stress has been reported to 
increase the expression of IL- $1 \alpha$, IL-1 $\beta$, IL-2, IL-3, IL-4, IL-5, IL-6, IL8, IL-10, IL-12(p70), CD40, IFN $\gamma$, MIP- $1 \alpha$, MIP-1 $\beta$, IL-13, IL-17, GMCSF, KC, RANTES, G-CSF and TNF $\alpha$, among others, as described by various authors and in a number of animal models (Cheng et al., 2015; Himmerich et al., 2013; Wang et al., 2015). In particular, the expression of IL- $1 \alpha$, IL-2, IL-3, IL-6, IL-9, IL-10, and G-CSF was increased $24 \mathrm{~h}$ after the last session of forced swimming.

Interestingly, elevated expression of pro-inflammatory cytokines correlates with depressive status in patients (Domenici et al., 2010; Licinio and Wong, 1999; Menard et al., 2015; Merendino et al., 2004; Schiepers et al., 2005; Tavakoli-Ardakani et al., 2015; Wong et al., 2008). In this regard, it has been proposed that inflammation induces depression-like symptoms (Cozzolongo et al., 2015; Dantzer et al., 2008; Dunn et al., 2005; Huang and Lin, 2015) through an increase in IL-6 (Gold et al., 2015). Here we demonstrate that acute stress caused by forced swimming increases the hippocampal protein levels of this cytokine. In line with this, other experimental manipulations that increase IL-6 also trigger the symptoms of depression (Murray et al., 2015; Xu et al., 2015), and, in fact, the measurement of IL-6 is considered a gold standard in the field of depression biomarkers (Bob et al., 2010) (also reviewed in Maes et al., (Maes et al., 2015)). Indeed, treatments with antidepressants are known to down-regulate IL-6 (Horowitz et al., 2015). Importantly, this cytokine exerts an epigenetic negative regulation of BDNF (Sharma et al., 2008). This negative regulation is involved in the reduction of connectivity between a number of crucial brain regions (Greicius et al., 2007).

In addition, another particularly important molecule in the field of neurodegeneration is the pro-inflammatory and chemoattractant cytokine eotaxin. This cytokine is increased in patients with depression (Grassi-Oliveira et al., 2012; Magalhaes et al., 2014), and here we demonstrate that it increases in response to acute stress. The activation of the eotaxin receptor inhibits the proliferative activity of neural precursors in the DG (Krathwohl and Kaiser, 2004), and increases in eotaxin levels have been demonstrated to decrease synaptic plasticity and cognition (Villeda et al., 2011).

With regard to the psycho-neuroendocrine system, the IGF-I and VEGF systems are heavily involved in the pathophysiology of $\mathrm{MD}$, as reflected by the fact that the administration of IGF-I has antidepressant effects (Malberg et al., 2007), the decreased levels of IGF-I have been related to depressive symptoms (Mitschelen et al., 2011), and that VEGF is needed for the behavioral effects of antidepressants (Warner-Schmidt and Duman, 2007). Interestingly, IGF-2 also plays a crucial role in controlling mood and affective disorders (Duan et al., 2014; Lisowski et al., 2013; Luo et al., 2015; Soubry et al., 2011). It has been proposed that IGF-I exerts some of its neuroprotective actions in depression by reducing the expression of pro-inflammatory cytokines such as IL-1, IL-6 and TNF (Park et al., 2011). Among the molecular components of the IGF-I cascade, IGFBP6 is considered a candidate as a biomarker for depression (Le-Niculescu et al., 2009). In addition, the expression of bFGF was reduced after forced swimming, a phenomenon that also occurs in depressed patients (Evans et al., 2004). Hence, it can be hypothesized that the combined effects of the proinflammatory mediators and increased circulating levels of GC, together with the decrease in the hippocampal trophic support, can orchestrate the impairment of newborn neuron maturation triggered by forced swimming.

\section{Concluding remarks}

Taken together, our data suggest that, in addition to increasing circulating levels of GC, forced swimming induces the appearance of a peculiar hippocampal inflammatory environment characterized by the expression of pro-inflammatory, phagocytosis- stimulating, chemoattractant, and neuroprotective elements, together with a reduction in several neurotrophic factor cascades. Given that inflammation produces long-lasting alterations in the hippocampus and that many of these mediators are known to be selectively involved in the development of MD, our findings may have clinical applications with respect to the treatment and diagnosis of MD and other stress-related disorders.

\section{Conflict of interest}

The authors declare no conflict of interest. This is an original manuscript that is not being considered for publication elsewhere.

\section{Funding}

This work was supported by grants from the Spanish Ministry of Health (SAF-2014-5040-P), and the Centro de Investigación Biomédica en Red sobre Enfermedades Neurodegenerativas (CIBERNED, ISCIII) (J. Ávila); and the Alzheimer's Association (2015-NIRG340709) (M. Llorens-Martín).

\section{Acknowledgments}

The authors thank E. García for help producing retroviral vectors and $\mathrm{C}$. Lois for providing the plasmids used for the production of the PSD95-GFP virus.

\section{Appendix A. Supplementary data}

Supplementary data associated with this article can be found, in the online version, at http://dx.doi.org/10.1016/j.bbi.2015.12.019.

\section{References}

Abelaira, H.M., Reus, G.Z., Neotti, M.V., Quevedo, J., 2014. The role of mTOR in depression and antidepressant responses. Life Sci. 101, 10-14.

Bob, P., Raboch, J., Maes, M., Susta, M., Pavlat, J., Jasova, D., Vevera, J., Uhrova, J. Benakova, H., Zima, T., 2010. Depression, traumatic stress and interleukin-6. J. Affect. Disord. 120, 231-234.

Cameron, H.A., Gould, E., 1994. Adult neurogenesis is regulated by adrenal steroids in the dentate gyrus. Neuroscience 61, 203-209.

Ceretta, L.B., Reus, G.Z., Abelaira, H.M., Jornada, L.K., Schwalm, M.T., Hoepers, N.J., Tomazzi, C.D., Gulbis, K.G., Ceretta, R.A., Quevedo, J., 2012. Increased prevalence of mood disorders and suicidal ideation in type 2 diabetic patients. Acta Diabetol. 49 (Suppl 1), S227-S234.

Cheng, Y., Jope, R.S., Beurel, E., 2015. A pre-conditioning stress accelerates increases in mouse plasma inflammatory cytokines induced by stress. BMC Neurosci. 16 , 31

Cozzolongo, R., Porcelli, P., Cariola, F., Giannuzzi, V., Lanzilotta, E., Gentile, M., Sonnante, G., Leandro, G., 2015. Serotonin gene polymorphisms and lifetime mood disorders in predicting interferon-induced depression in chronic hepatitis C. J. Affect. Disord. 183, 90-97.

Dantzer, R., O’Connor, J.C., Freund, G.G., Johnson, R.W., Kelley, K.W., 2008. From inflammation to sickness and depression: when the immune system subjugates the brain. Nat. Rev. Neurosci. 9, 46-56.

Detke, M.J., Rickels, M., Lucki, I., 1995. Active behaviors in the rat forced swimming test differentially produced by serotonergic and noradrenergic antidepressants. Psychopharmacology 121, 66-72.

Domenici, E., Wille, D.R., Tozzi, F., Prokopenko, I., Miller, S., McKeown, A., Brittain, C., Rujescu, D., Giegling, I., Turck, C.W., Holsboer, F., Bullmore, E.T., Middleton, L. Merlo-Pich, E., Alexander, R.C., Muglia, P., 2010. Plasma protein biomarkers for depression and schizophrenia by multi analyte profiling of case-control collections. PLoS ONE 5, e9166.

Duan, D., Yang, X., Ya, T., Chen, L., 2014. Hippocampal gene expression in a rat model of depression after electroacupuncture at the Baihui and Yintang acupoints. Neural Regener. Res. 9, 76-83.

Dunn, A.J., Swiergiel, A.H., de Beaurepaire, R., 2005. Cytokines as mediators of depression: what can we learn from animal studies? Neurosci. Biobehav. Rev. 29, 891-909.

Evans, S.J., Choudary, P.V., Neal, C.R., Li, J.Z., Vawter, M.P., Tomita, H., Lopez, J.F., Thompson, R.C., Meng, F., Stead, J.D., Walsh, D.M., Myers, R.M., Bunney, W.E. Watson, S.J., Jones, E.G., Akil, H., 2004. Dysregulation of the fibroblast growth factor system in major depression. Proc. Natl. Acad. Sci. U.S.A. 101, 1550615511. 
Fitzsimons, C.P., van Hooijdonk, L.W., Schouten, M., Zalachoras, I., Brinks, V., Zheng, T., Schouten, T.G., Saaltink, D.J., Dijkmans, T., Steindler, D.A., Verhaagen, J., Verbeek, F.J., Lucassen, P.J., de Kloet, E.R., Meijer, O.C., Karst, H., Joels, M., Oitzl, M.S., Vreugdenhil, E., 2013. Knockdown of the glucocorticoid receptor alters functional integration of newborn neurons in the adult hippocampus and impairs fear-motivated behavior. Mol. Psychiatry 18, 993-1005.

Frank, M.G., Baratta, M.V., Sprunger, D.B., Watkins, L.R., Maier, S.F., 2007. Microglia serve as a neuroimmune substrate for stress-induced potentiation of CNS proinflammatory cytokine responses. Brain Behav. Immun. 21, 47-59.

Frank, M.G., Hershman, S.A., Weber, M.D., Watkins, L.R., Maier, S.F., 2014. Chronic exposure to exogenous glucocorticoids primes microglia to pro-inflammatory stimuli and induces NLRP3 mRNA in the hippocampus. Psychoneuroendocrinology 40, 191-200.

Garcia, A., Steiner, B., Kronenberg, G., Bick-Sander, A., Kempermann, G., 2004. Agedependent expression of glucocorticoid- and mineralocorticoid receptors on neural precursor cell populations in the adult murine hippocampus. Aging Cell 3, 363-371.

Garthe, A., Behr, J., Kempermann, G., 2009. Adult-generated hippocampal neurons allow the flexible use of spatially precise learning strategies. PLoS ONE 4, e5464.

Gersner, R., Dar, D.E., Shabat-Simon, M., Zangen, A., 2005. Behavioral analysis during the forced swimming test using a joystick device. J. Neurosci. Methods 143, 117-121.

Gold, P.W., Machado-Vieira, R., Pavlatou, M.G., 2015. Clinical and biochemical manifestations of depression: relation to the neurobiology of stress. Neural Plast. 2015, 581976.

Gould, E., Woolley, C.S., McEwen, B.S., 1990. Short-term glucocorticoid manipulations affect neuronal morphology and survival in the adult dentate gyrus. Neuroscience 37, 367-375.

Gould, E., Cameron, H.A., Daniels, D.C., Woolley, C.S., McEwen, B.S., 1992. Adrenal hormones suppress cell division in the adult rat dentate gyrus. J. Neurosci. 12 3642-3650.

Grassi-Oliveira, R., Brieztke, E., Teixeira, A., Pezzi, J.C., Zanini, M., Lopes, R.P., Bauer, M.E., 2012. Peripheral chemokine levels in women with recurrent major depression with suicidal ideation. Rev. Bras. Psiquiatr. 34, 71-75.

Greicius, M.D., Flores, B.H., Menon, V., Glover, G.H., Solvason, H.B., Kenna, H., Reiss A.L., Schatzberg, A.F., 2007. Resting-state functional connectivity in major depression: abnormally increased contributions from subgenual cingulate cortex and thalamus. Biol. Psychiatry 62, 429-437.

Hellwig, S., Brioschi, S., Dieni, S., Frings, L., Masuch, A., Blank, T., Biber, K., 2015 Altered microglia morphology and higher resilience to stress-induced depression-like behavior in CX3CR1-deficient mice. Brain Behav. Immun.

Himmerich, H., Fischer, J., Bauer, K., Kirkby, K.C., Sack, U., Krugel, U., 2013. Stressinduced cytokine changes in rats. Eur. Cytokine Netw. 24, 97-103.

Hinwood, M., Tynan, R.J., Charnley, J.L., Beynon, S.B., Day, T.A., Walker, F.R., 2013. Chronic stress induced remodeling of the prefrontal cortex: structural reorganization of microglia and the inhibitory effect of minocycline. Cereb. Cortex $23,1784-1797$.

Horowitz, M.A., Wertz, J., Zhu, D., Cattaneo, A., Musaelyan, K., Nikkheslat, N., Thuret, S., Pariante, C.M., Zunszain, P.A., 2015. Antidepressant compounds can be both pro- and anti-inflammatory in human hippocampal cells. Int. J. Neuropsychopharmacol. 18.

Hoyo-Becerra, C., Schlaak, J.F., Hermann, D.M., 2014. Insights from interferon-alpharelated depression for the pathogenesis of depression associated with inflammation. Brain Behav. Immun. 42, 222-231.

Huang, T.L., Lin, C.C., 2015. Advances in biomarkers of major depressive disorder. Adv. Clin. Chem. 68, 177-204.

Iseme, R.A., McEvoy, M., Kelly, B., Agnew, L., Attia, J., Walker, F.R., 2014. Autoantibodies and depression: evidence for a causal link? Neurosci. Biobehav. Rev. 40, 62-79.

Kelsch, W., Lin, C.W., Lois, C., 2008. Sequential development of synapses in dendritic domains during adult neurogenesis. Proc. Natl. Acad. Sci. U.S.A. 105, 1680316808

Kettenmann, H., Kirchhoff, F., Verkhratsky, A., 2013. Microglia: new roles for the synaptic stripper. Neuron $77,10-18$.

Krathwohl, M.D., Kaiser, J.L., 2004. Chemokines promote quiescence and survival of human neural progenitor cells. Stem Cells 22, 109-118.

Kreisel, T., Frank, M.G., Licht, T., Reshef, R., Ben-Menachem-Zidon, O., Baratta, M.V. Maier, S.F., Yirmiya, R., 2014. Dynamic microglial alterations underlie stressinduced depressive-like behavior and suppressed neurogenesis. Mol. Psychiatry 19, 699-709.

Lee, W., Moon, M., Kim, H.G., Lee, T.H., Oh, M.S., 2015. Heat stress-induced memory impairment is associated with neuroinflammation in mice. J. Neuroinflammation 12, 102.

Lehto, S.M., Huotari, A., Niskanen, L., Herzig, K.H., Tolmunen, T., Viinamaki, H. Koivumaa-Honkanen, H., Honkalampi, K., Sinikallio, S., Ruotsalainen, H. Hintikka, J., 2010. Serum IL-7 and G-CSF in major depressive disorder. Prog. Neuropsychopharmacol. Biol. Psychiatry 34, 846-851.

Le-Niculescu, H., Kurian, S.M., Yehyawi, N., Dike, C., Patel, S.D., Edenberg, H.J., Tsuang, M.T., Salomon, D.R., Nurnberger Jr., J.I., Niculescu, A.B., 2009. Identifying blood biomarkers for mood disorders using convergent functional genomics. Mol. Psychiatry 14, 156-174.

Licinio, J., Wong, M.L., 1999. The role of inflammatory mediators in the biology of major depression: central nervous system cytokines modulate the biological substrate of depressive symptoms, regulate stress-responsive systems, and contribute to neurotoxicity and neuroprotection. Mol. Psychiatry 4, 317 327.
Lisowski, P., Juszczak, G.R., Goscik, J., Stankiewicz, A.M., Wieczorek, M., Zwierzchowski, L., Swiergiel, A.H., 2013. Stress susceptibility-specific phenotype associated with different hippocampal transcriptomic responses to chronic tricyclic antidepressant treatment in mice. BMC Neurosci. 14, 144.

Llorens-Martin, M., Trejo, J.L., 2011. Mifepristone prevents stress-induced apoptosis in newborn neurons and increases AMPA receptor expression in the dentate gyrus of C57/BL6 mice. PLOS ONE 6, e28376.

Llorens-Martin, M.V., Rueda, N., Martinez-Cue, C., Torres-Aleman, I., Florez, J., Trejo, J.L., 2007. Both increases in immature dentate neuron number and decreases of immobility time in the forced swim test occurred in parallel after environmental enrichment of mice. Neuroscience 147, 631-638.

Llorens-Martin, M., Fuster-Matanzo, A., Teixeira, C.M., Jurado-Arjona, J., Ulloa, F., Defelipe, J., Rabano, A., Hernandez, F., Soriano, E., Avila, J., 2013. GSK-3beta overexpression causes reversible alterations on postsynaptic densities and dendritic morphology of hippocampal granule neurons in vivo. Mol. Psychiatry 18, 451-460.

Llorens-Martin, M., Jurado-Arjona, J., Fuster-Matanzo, A., Hernandez, F., Rabano, A., Avila, J., 2014. Peripherally triggered and GSK-3beta-driven brain inflammation differentially skew adult hippocampal neurogenesis, behavioral pattern separation and microglial activation in response to ibuprofen. Transl. Psychiatry 4, e463.

Llorens-Martin, M., Jurado-Arjona, J., Avila, J., Hernandez, F., 2015. Novel connection between newborn granule neurons and the hippocampal CA2 field. Exp. Neurol. 263, 285-292.

Luo, Y.W., Xu, Y., Cao, W.Y., Zhong, X.L., Duan, J., Wang, X.Q., Hu, Z.L., Li, F., Zhang, J. Y., Zhou, M., Dai, R.P., Li, C.Q., 2015. Insulin-like growth factor 2 mitigates depressive behavior in a rat model of chronic stress. Neuropharmacology 89, 318-324.

Madrigal, J.L., Moro, M.A., Lizasoain, I., Lorenzo, P., Fernandez, A.P., Rodrigo, J., Bosca, L., Leza, J.C., 2003. Induction of cyclooxygenase-2 accounts for restraint stressinduced oxidative status in rat brain. Neuropsychopharmacology 28, 15791588.

Maes, M., Nowak, G., Caso, J.R., Leza, J.C., Song, C., Kubera, M., Klein, H., Galecki, P., Noto, C., Glaab, E., Balling, R., Berk, M., 2015. Toward omics-based, systems biomedicine, and path and drug discovery methodologies for depressioninflammation research. Mol. Neurobiol.

Magalhaes, P.V., Jansen, K., Stertz, L., Ferrari, P., Pinheiro, R.T., da Silva, R.A., Kapczinski, F., 2014. Peripheral eotaxin-1 (CCL11) levels and mood disorder diagnosis in a population-based sample of young adults. J. Psychiatr. Res. 48, 13-15.

Malberg, J.E., Eisch, A.J., Nestler, E.J., Duman, R.S., 2000. Chronic antidepressant treatment increases neurogenesis in adult rat hippocampus. J. Neurosci. 20, 9104-9110.

Malberg, J.E., Platt, B., Rizzo, S.J., Ring, R.H., Lucki, I., Schechter, L.E., RosenzweigLipson, S., 2007. Increasing the levels of insulin-like growth factor-I by an IGF binding protein inhibitor produces anxiolytic and antidepressant-like effects. Neuropsychopharmacology 32, 2360-2368.

Menard, C., Hodes, G.E., Russo, S.J., 2015. Pathogenesis of depression: insights from human and rodent studies. Neuroscience.

Merendino, R.A., Di Pasquale, G., De Luca, F., Di Pasquale, L., Ferlazzo, E., Martino, G., Palumbo, M.C., Morabito, F., Gangemi, S., 2004. Involvement of fractalkine and macrophage inflammatory protein-1 alpha in moderate-severe depression. Mediators Inflamm. 13, 205-207.

Meshi, D., Drew, M.R., Saxe, M., Ansorge, M.S., David, D., Santarelli, L., Malapani, C. Moore, H., Hen, R., 2006. Hippocampal neurogenesis is not required for behavioral effects of environmental enrichment. Nat. Neurosci. 9, 729-731.

Milior, G., Lecours, C., Samson, L., Bisht, K., Poggini, S., Pagani, F., Deflorio, C., Lauro, C., Alboni, S., Limatola, C., Branchi, I., Tremblay, M.E., Maggi, L., 2015. Fractalkine receptor deficiency impairs microglial and neuronal responsiveness to chronic stress. Brain Behav. Immun.

Mitschelen, M., Yan, H., Farley, J.A., Warrington, J.P., Han, S., Herenu, C.B., Csiszar, A., Ungvari, Z., Bailey-Downs, L.C., Bass, C.E., Sonntag, W.E., 2011. Long-term deficiency of circulating and hippocampal insulin-like growth factor I induces depressive behavior in adult mice: a potential model of geriatric depression. Neuroscience 185, 50-60.

Moghaddam, B., Bolinao, M.L., Stein-Behrens, B., Sapolsky, R., 1994. Glucocorticoids mediate the stress-induced extracellular accumulation of glutamate. Brain Res. 655, 251-254.

Murray, C., Griffin, E.W., O’Loughlin, E., Lyons, A., Sherwin, E., Ahmed, S., Stevenson, N.J., Harkin, A., Cunningham, C., 2015. Interdependent and independent roles of type I interferons and IL-6 in innate immune, neuroinflammatory and sickness behaviour responses to systemic poly I:C. Brain Behav. Immun.

Nair, A., Bonneau, R.H., 2006. Stress-induced elevation of glucocorticoids increases microglia proliferation through NMDA receptor activation. J. Neuroimmunol. $171,72-85$.

Nguyen, K.T., Deak, T., Owens, S.M., Kohno, T., Fleshner, M., Watkins, L.R., Maier, S.F., 1998. Exposure to acute stress induces brain interleukin-1beta protein in the rat. J. Neurosci. 18, 2239-2246.

Paolicelli, R.C., Bisht, K., Tremblay, M.E., 2014. Fractalkine regulation of microglial physiology and consequences on the brain and behavior. Front. Cell. Neurosci. 8, 129.

Park, S.E., Dantzer, R., Kelley, K.W., McCusker, R.H., 2011. Central administration of insulin-like growth factor-I decreases depressive-like behavior and brain cytokine expression in mice. J. Neuroinflammation 8, 12.

Pocock, J.M., Kettenmann, H., 2007. Neurotransmitter receptors on microglia. Trends Neurosci. 30, 527-535. 
Santarelli, L., Saxe, M., Gross, C., Surget, A., Battaglia, F., Dulawa, S., Weisstaub, N. Lee, J., Duman, R., Arancio, O., Belzung, C., Hen, R., 2003. Requirement of hippocampal neurogenesis for the behavioral effects of antidepressants. Science 301, 805-809.

Schiepers, O.J., Wichers, M.C., Maes, M., 2005. Cytokines and major depression. Prog. Neuropsychopharmacol. Biol. Psychiatry 29, 201-217.

Sharma, R.P., Tun, N., Grayson, D.R., 2008. Depolarization induces downregulation of DNMT1 and DNMT3a in primary cortical cultures. Epigenetics 3, 74-80.

Sierra, A., Encinas, J.M., Deudero, J.J., Chancey, J.H., Enikolopov, G., OverstreetWadiche, L.S., Tsirka, S.E., Maletic-Savatic, M., 2010. Microglia shape adult hippocampal neurogenesis through apoptosis-coupled phagocytosis. Cell Stem Cell 7, 483-495.

Slusarczyk, J., Trojan, E., Glombik, K., Budziszewska, B., Kubera, M., Lason, W., Popiolek-Barczyk, K., Mika, J., Wedzony, K., Basta-Kaim, A., 2015. Prenatal stress is a vulnerability factor for altered morphology and biological activity of microglia cells. Front. Cell. Neurosci. 9, 82.

Soubry, A., Murphy, S., Huang, Z., Murtha, A., Schildkraut, J., Jirtle, R., Wang, F., Kurtzberg, J., Demark-Wahnefried, W., Forman, M., Hoyo, C., 2011. The effects of depression and use of antidepressive medicines during pregnancy on the methylation status of the IGF2 imprinted control regions in the offspring. Clin. Epigenetics 3, 2.

Sugama, S., Fujita, M., Hashimoto, M., Conti, B., 2007. Stress induced morphological microglial activation in the rodent brain: involvement of interleukin-18. Neuroscience 146, 1388-1399.

Tavakoli-Ardakani, M., Mehrpooya, M., Mehdizadeh, M., Hajifathali, A., Abdolahi, A., 2015. Association between Interlukin-6 (IL-6), Interlukin-10 (IL-10) and depression in patients undergoing Hematopoietic stem cell transplantation. Int. J. Hematol. Oncol. Stem Cell Res. 9, 80-87.

Trapp, B.D., Wujek, J.R., Criste, G.A., Jalabi, W., Yin, X., Kidd, G.J., Stohlman, S. Ransohoff, R., 2007. Evidence for synaptic stripping by cortical microglia. Glia $55,360-368$.

Tremblay, M.E., Majewska, A.K., 2011. A role for microglia in synaptic plasticity? Commun. Integr. Biol. 4, 220-222.

Tynan, R.J., Naicker, S., Hinwood, M., Nalivaiko, E., Buller, K.M., Pow, D.V., Day, T.A., Walker, F.R., 2010. Chronic stress alters the density and morphology of microglia in a subset of stress-responsive brain regions. Brain Behav. Immun. 24, 1058-1068.

Veldhuis, H.D., De Korte, C.C., De Kloet, E.R., 1985. Glucocorticoids facilitate the retention of acquired immobility during forced swimming. Eur. J. Pharmacol. $115,211-217$.

Villeda, S.A., Luo, J., Mosher, K.I., Zou, B., Britschgi, M., Bieri, G., Stan, T.M., Fainberg N., Ding, Z., Eggel, A., Lucin, K.M., Czirr, E., Park, J.S., Couillard-Despres, S., Aigner, L., Li, G., Peskind, E.R., Kaye, J.A., Quinn, J.F., Galasko, D.R., Xie, X.S., Rando, T.A., Wyss-Coray, T., 2011. The ageing systemic milieu negatively regulates neurogenesis and cognitive function. Nature 477, 90-94.

Wake, H., Moorhouse, A.J., Jinno, S., Kohsaka, S., Nabekura, J., 2009. Resting microglia directly monitor the functional state of synapses in vivo and determine the fate of ischemic terminals. J. Neurosci. 29, 3974-3980.

Walker, F.R., Nilsson, M., Jones, K., 2013. Acute and chronic stress-induced disturbances of microglial plasticity, phenotype and function. Curr. Drug Targets $14,1262-1276$.

Wang, L.I., Liu, F., Luo, Y., Zhu, L., Li, G., 2015. Effect of acute heat stress on adrenocorticotropic hormone, cortisol, interleukin-2, interleukin-12 and apoptosis gene expression in rats. Biomed. Rep. 3, 425-429.

Warner-Schmidt, J.L., Duman, R.S., 2007. VEGF is an essential mediator of the neurogenic and behavioral actions of antidepressants. Proc. Natl. Acad. Sci. U.S. A. $104,4647-4652$.

Wong, M.L., Dong, C., Maestre-Mesa, J., Licinio, J., 2008. Polymorphisms in inflammation-related genes are associated with susceptibility to major depression and antidepressant response. Mol. Psychiatry 13, 800-812.

Woolley, C.S., Gould, E., McEwen, B.S., 1990. Exposure to excess glucocorticoids alters dendritic morphology of adult hippocampal pyramidal neurons. Brain Res. 531, 225-231.

Xu, Y., Sheng, H., Tang, Z., Lu, J., Ni, X., 2015. Inflammation and increased IDO in hippocampus contribute to depression-like behavior induced by estrogen deficiency. Behav. Brain Res. 288, 71-78.

Zhao, C., Teng, E.M., Summers Jr., R.G., Ming, G.L., Gage, F.H., 2006. Distinct morphological stages of dentate granule neuron maturation in the adult mouse hippocampus. J. Neurosci. 26, 3-11. 